\title{
Modificações paisagísticas e implicações térmicas no distrito administrativo de Belém, Pará
}

\section{Landscaping modifications and thermal implications in administrative district of Belem, Para, Brazil}

\author{
Tássia Toyoi Gomes Takashima-Oliveira ${ }^{1 *}$, Paulo Eduardo da Silva Bezerra ${ }^{2}$, Altem Nascimento Pontes ${ }^{3}$, Ana Cláudia \\ Cadeira Tavares-Martins ${ }^{4}$
}

\begin{abstract}
Resumo: As modificações paisagísticas no uso e cobertura da terra podem implicar em alterações na dinâmica de ecossistemas e no clima local. Assim, objetivou-se verificar se o padrão de uso e cobertura da terra contribui para a existência e ou aumento de ilhas de calor no distrito de Mosqueiro, Pará. Foram levantados dados qualitativos por meio de entrevistas não formais com moradores para se conhecer as formas de uso e manejo das propriedades. Os dados quantitativos foram obtidos através de imagens temáticas da ilha correspondentes ao período menos chuvoso da região nos anos de 2010, 2013 e 2015 . A classificação do uso e cobertura da terra na ilha de Mosqueiro seguiu o critério não supervisionado. Os dados de temperatura de superfície (TS) foram obtidos por meio dos valores de radiância espectral, da banda termal dos satélites Landsat 5 e 8 . Para determinação de ilha de calor, considerou-se a resultante da diferença das temperaturas entre a classe de área urbana e a de floresta. No período de 2010 a 2015, constatou-se redução de área em 9,1\% de floresta, pelo crescimento da infraestrutura urbana e pelo desmatamento na região, fato corroborado com a percepção dos moradores locais. Essas modificações resultaram em mudanças na TS, com aumento médio de $5.15{ }^{\circ} \mathrm{C}$, mesmo que não se tenha constatado a ocorrência de ilha de calor no espaço urbano. Diante do exposto, verificou-se que as variações da TS estão inteiramente relacionadas às mudanças nas classes de uso e cobertura da terra na ilha e que tende a intensificar sem o planejamento ambiental adequado.
\end{abstract}

Palavras-chave: Ilha de Mosqueiro; Uso e cobertura da terra; Temperatura de superfície; Urbanização; Ilha de calor.

\begin{abstract}
Landscaping modifications in land use and land cover may cause changes in the dynamics of ecosystems and in the local climate. Therefore, the aim was to verify if the land use and coverage pattern contribute to the existence and/or increasing of heat islands in the district of Mosqueiro-PA. Qualitative data were collected took place through non-formal interviews with residentes to know the ways of using and managing the properties. The quantitative data were obtained through thematic images of the island corresponding to the less rainy period of the region in the years of 2010, 2013 and 2015. The classification of land use and land cover in Mosqueiro island followed the unsupervised criterion. The surface temperature data (TS) were obtained by averages of spectral radiance values of thermal band of the Landsat satellites. The heat island determination considered the resultant of the temperature difference between the urban and forest area. In the period from 2010 to 2015 , there was a reduction of $9.1 \%$ in forest area due to the increase in urban infrastructure and deforestation in the region, which is supported by the perception of sites residents. These modifications resulted in changes in TS, with an average increase of 5.15 ${ }^{\circ} \mathrm{C}$, even though the occurrence of heat island in the urban space of the island was not detected. Accordingly, it is concluded that TS variations are entirely related to changes in land use and land cover classes on the island and that it tends to intensify without adequate environmental planning.
\end{abstract}

Key words: Mosqueiro Island. Land use and land cover. Surface temperature. Urbanization. Heat island.

\footnotetext{
*Autor para correspondência

Recebido para publicação em 14/02/2018; aprovado em 28/06/2018

${ }^{1}$ Mestre em Ciências Ambientais, Universidade do Estado do Pará, Belém, tassiatka@ gmail.com

${ }^{2}$ Mestrando no Programa de Pós-Graduação em Engenharia Civil, Universidade Federal do Pará, Belém, pauloeduardoea@ gmail.com

${ }^{3}$ Doutor em Ciências, Universidade do Estado do Pará, Belém, altempontes@ hotmail.com

${ }^{4}$ Doutora em Botânica, Universidade do Estado do Pará, Belém, tavaresmartins7@gmail.com
} 


\section{INTRODUÇÃO}

A região amazônica perpassou por modelos e ciclos de desenvolvimento econômico com enfoque no agroextrativismo, demonstrando um cenário de uso da terra determinado por fatores de mercado, com destaque em atividades madeireiras, pecuárias e agrícolas (PRATES; BACHA, 2011). Essas atividades são associadas às altas taxas de desmatamento na Amazônia Legal, mesmo diante de medidas que visem a redução desses valores (FERREIRA et al., 2005).

Os planos de desenvolvimento para a Amazônia Legal também estimularam o desmatamento das áreas florestais na região em decorrência às grandes obras de infraestrutura e ao crescimento populacional (FEARNSIDE; LAURANCE, 2012; PRATES; BACHA, 2011). Deste modo, a urbanização desorganizada se expandiu pelo território amazônico, tendo como consequência a alta conversão de áreas de floresta em estruturas de elevações geométricas, com poucas ou ausência de áreas verdes, apresentando alto revestimento e impermeabilização do solo nos aglomerados urbanos formados (CORREA et al., 2015). Sem planejamento adequado essas modificações paisagísticas implicaram em sérios impactos para a biota local (VIEIRA et al., 2005), para os serviços ecossistêmicos (FEARNSIDE; LAURANCE, 2012), e interferiu diretamente no clima local e regional (XIAO; WENG, 2007).

A formação de ilhas de calor nos centros urbanos é um dos efeitos das modificações nos atributos biofísicos da paisagem sobre clima local. Esse processo, é essencialmente definido pela diferença de temperatura entre a área urbana e zonas periféricas pouco construídas (AMORIM et al., 2009). No Brasil, esse fenômeno foi registrado em diversas cidades com alto grau de urbanização ou com intensa atividade industrial, tais como Vitória - ES (CORREA et al., 2015), São Carlos - SP (BARBOSA; VECCHIA, 2009), Goiânia GO (NASCIMENTO; OLIVEIRA, 2011), Manaus - AM (SOUZA; ALVALÁ, 2012) e Belém - PA (SOUZA, 2012).

Assim como as características estruturais das cidades influenciam negativamente para o aumento da temperatura de superfície, a vegetação exerce grande importância na redução dessa variável (SOUZA; ALVALÁ, 2012). O processo fisiológico de evapotranspiração das árvores é o responsável por condicionar tanto a temperatura como a umidade relativa do ar em seu entorno, proporcionando melhores sensações térmicas ao ser humano e ao ambiente circundante, função denominada como termorregulação (ABREU; LABAKI, 2010).

Diante de uma paisagem densamente construída pelo processo de urbanização na Região Metropolitana de Belém (RMB), destaca-se a ilha de Mosqueiro por constituir ainda uma ampla extensão de floresta contínua remanescente. No entanto, essa ilha vivencia um processo intenso de modificações territoriais, principalmente, ao apelo turístico de vastas extensões de praia de água doce, associada às acessibilidade e proximidade da ilha com o centro urbano da RMB.

O baixo valor imobiliário, em conjunto com características supracitadas, impulsionou a ocupação na ilha, tornando Mosqueiro um espaço amplamente visado e ligeiramente apropriado por moradores permanentes e temporários (CABRAL et al., 2015). Durante o período de alta estação de veraneio da região, o contingente populacional de 28 mil habitantes, aproximadamente, atinge até $150 \mathrm{mil}$ pessoas (GONÇALVES et al., 2016; RIBEIRO et al., 2013).

Além da pressão ambiental provinda da questão turística na ilha, as práticas agrícolas desenvolvidas por membros de comunidades tradicionais ali estabelecidas, também contribuem para as transformações na paisagem, visto que o modo convencional de corte e queima da vegetação no preparo do solo e a produção de carvão mineral resulta em vastas áreas de florestas remanescente desmatadas (FERREIRA, 2012).

Desta forma, objetivou-se verificar se o padrão de uso e cobertura da terra contribui para a existência e/ou aumento de ilhas de calor no distrito de Mosqueiro-PA, para subsidiar futuros planejamentos, gestão e administração da ocupação urbana de modo ordenado e racional da área.

\section{MATERIAL E MÉTODOS}

A abordagem da pesquisa possui tanto uma vertente qualitativa, quanto quantitativa, ambas direcionadas para compreender a dinâmica de uso e cobertura da terra na ilha de Mosqueiro nos anos de 2010, 2013 e 2015 e suas possíveis implicações ambientais no clima local.

A Ilha de Mosqueiro, localizada geograficamente na costa oriental do rio Pará, em frente à baia do Guajará, com cerda de 27 mil habitantes (IBGE, 2018), destaca-se pela riqueza de habitats, o que possibilita a ocorrência de alta diversidade de espécies florísticas (COSTA; PIETROBOM, 2007). A principal fitofisionomia da ilha é composta por floresta ombrófila densa, embora as várzeas e as florestas secundárias possuam expressividade na área (GONÇALVES et al., 2016). Além de estar a ilha apresenta grande vocação turística pela vasta extensão de praias de água doce (QUARESMA et al., 2008), bem como pela beleza cênica da paisagem natural da ilha composta por um amplo domínio de floresta natural remanescente (TAVARES et al., 2007).

Instituída pela Lei $\mathrm{n}^{\circ} 753$ de 1901 como distrito administrativo do município de Belém, a ilha está localizada à cerca de $70 \mathrm{~km}$ do centro urbano da Região metropolitana de Belém e interligada ao município por meio da rodovia Augusto Meira Filho (PA-319), conforme se observa na Figura 1 (CABRAL et al., 2015). Além de estar inserida na faixa equatorial, onde o clima predominante da região é o tipo Af, equatorial úmido, conforme a classificação de Köppen, sendo caracterizado pela sazonalidade regional na ocorrência de um período mais chuvoso que se estende de dezembro a maio com incidência de aproximadamente $90 \%$ da precipitação anual e de um período menos chuvoso de junho a novembro (SANTOS et al., 2014). Quando há influência de fenômenos climáticos em grande escala como El Niño e La Niña, altera o padrão de sazonalidade da região, causando modificações na precipitação e temperatura do ar em diferentes lugares (OLIVEIRA et al., 2015). 
Figura 1. Localização da área de estudo, distrito administrativo do município de Belém, Ilha de Mosqueiro, Pará, Brasil.
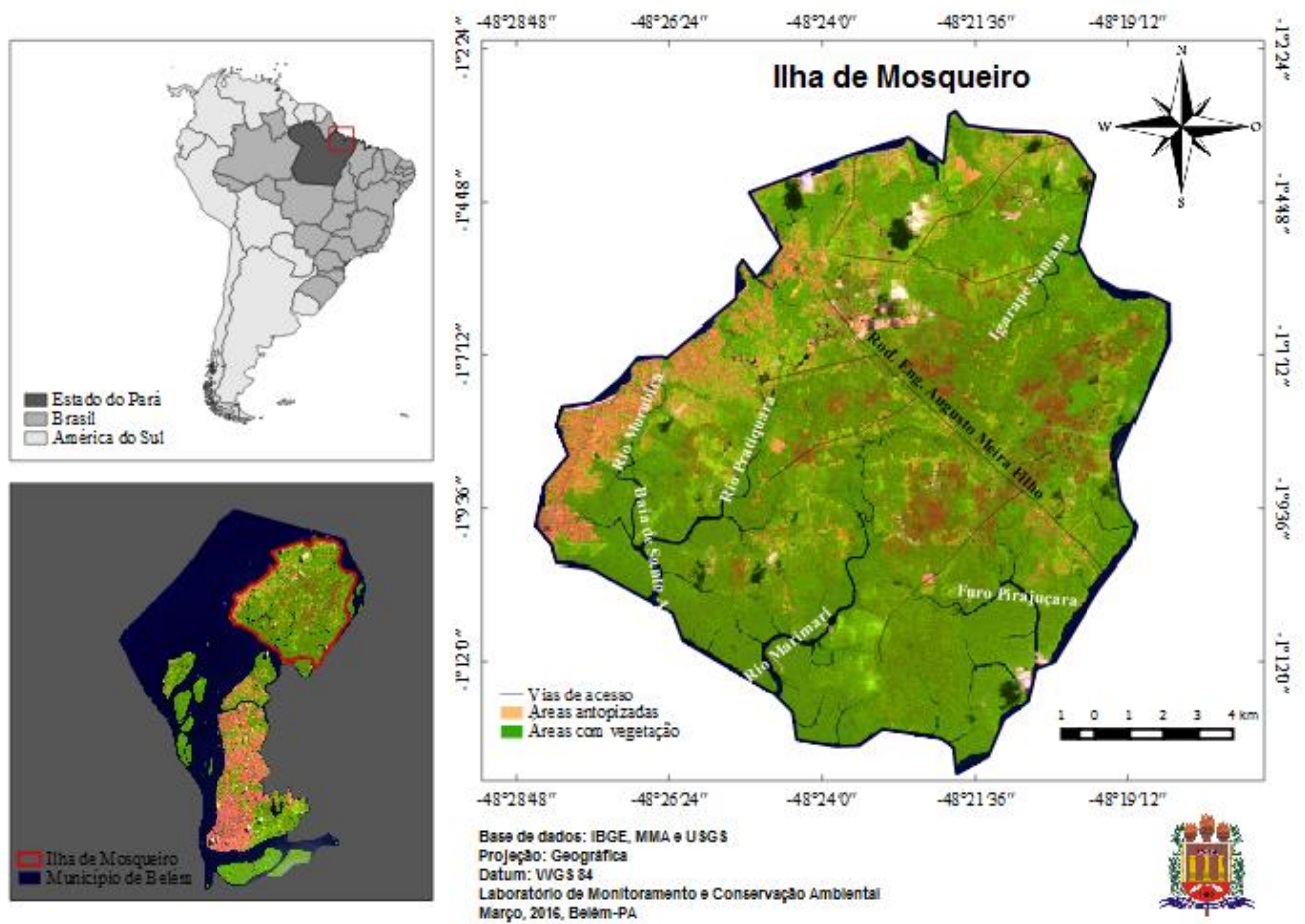

Fonte: Autores (2018).

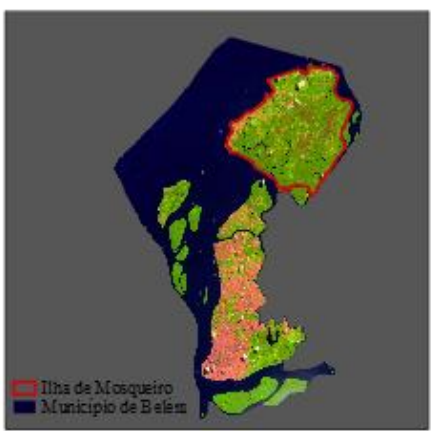

Além da vocação turística, a ilha tem destaque pelos produtos da economia ribeirinha como camarão, açaí e farinha de mandioca (GONÇALVES et al., 2016). Esses produtos são provenientes do trabalho de membros de cinco comunidades tradicionais estabelecidas na ilha: Espírito Santo, Castanhal do Mari-Mari, Porto Pelé, Caruaru e Baia de Santo Antônio (QUARESMA et al., 2008).

\section{Aspecto quantitativo}

A imagens temáticas da dinâmica de uso e cobertura da terra da ilha de Mosqueiro, nos anos de 2010, 2013 e 2015, foram geradas com imagens base do sistema online United States Geological Survey (USGS), correspondendo ao período menos chuvoso da região, datadas em 18 de setembro de 2010, 06 de novembro de 2013 e 02 de agosto de 2015, às 9: $45 \mathrm{~h}, 10 \mathrm{~h}$ e $10 \mathrm{~h}$, sucessivamente. O tratamento e análise dos dados das imagens em todas as etapas foram realizados pelo software ArcGis $10.1^{\circledR}$, dos satélites Landsat 5 e 8 , sensor Thematic Mapper (TM) e resolução espacial de 30 metros. Para ambos os satélites as imagens obtidas possuem orbita ponto 223/061 (COELHO; CORREA, 2013).

A classificação do uso e cobertura da terra na ilha de Mosqueiro seguiu o critério não supervisionado, adotado por Messias (2012), sendo que as chaves de classificação são de acordo com o conjunto de características, considerando a cor, textura e forma da imagem (Quadro 1). Foram utilizadas as bandas espectrais 6, 5 e 4 do Landsat 8, para os anos de 2013 e 2015, e as bandas 7, 4 e 2 do satélite Landsat 5, para a imagem de 2010.
Quadro 1. Extensão territorial das classes de uso e cobertura na ilha de Mosqueiro, Pará, nos anos de 2010, 2013 e 2015.

\begin{tabular}{|c|c|c|c|}
\hline Classe & Cor & Textura & Forma \\
\hline Água & Azul & Lisa & Irregular \\
\hline Área urbana & $\begin{array}{c}\text { Rosa } \\
\text { Escuro }\end{array}$ & Rugosa & Geométrica \\
\hline Solo exposto & $\begin{array}{c}\text { Rosa } \\
\text { Escuro }\end{array}$ & Lisa & Irregular \\
\hline Floresta & Verde & Media & Geométrica \\
\hline Área não observada & Branco & Rugosa & Geométrica \\
\hline
\end{tabular}

Para verificação dos efeitos na mudança paisagística sobre a temperatura de superfície houve a conversão das imagens raster em valores de temperatura de superfície, pela seleção das bandas termais 6 e 10 dos satélites Landsat 5 e 8, respectivamente, haja vista que a banda termal do Landsat mede a quantidade de energia radiante infravermelha emitida nas superfícies, útil em localizar atividades geotermal.

Durante o processamento geográfico, determinou-se inicialmente os níveis de radiância espectral de cada imagem, apurados pela Eq. 1 (COELHO; CORREA, 2013).

$$
\mathrm{L} \lambda=\mathrm{ML} \text { Qcal }+\mathrm{AL}
$$

Em que: $L \lambda$ - a radiância espectral do sensor de abertura, expressa em Watts. $\left(\mathrm{m}^{2} \mathrm{sr} \mu \mathrm{m}\right)-1$; ML - fator multiplicativo de redimensionamento da banda termal; Qcal- valor quantizado e calibrado pelo pixel em número digital da imagem banda termal; AL - fator de redimensionamento aditivo específico da banda termal.

Em sequência, a radiância espectral foi convertida em temperatura de superfície, na escala Kelvin, por meio da Eq. 2 .

$$
\mathrm{T}=\mathrm{K} 2 /(\operatorname{Ln}(\mathrm{K} 1 / \mathrm{L} \lambda+1))
$$


Em que: $\mathrm{T}$ - temperatura efetiva no satélite, em Kelvin (K); K2 - constante de calibração 2 em K; K1 - constante de calibração 1 em K.

Os dados de temperatura foram convertidos para graus Celsius e submetido, juntamente com os dados de área das classes de uso e cobertura da terra, à análise de variância (ANOVA) e regressão linear simples pelo software Bioestat 5.0 (AYRES et al., 2007). Ressalta-se que o conjunto de dados foram transformados pela função $\operatorname{Ln}(\mathrm{x})$ para atender a distribuição normal e homogênea de acordo com a aplicação dos testes de Lilliefors e de Levene, respectivamente, para aplicação da análise de variância.

A determinação da existência de ilha de calor foi realizada por meio da resultante da diferença das temperaturas de superfície $(\Delta \mathrm{T})$ entre a classe de área urbana e a classe de seu entorno (floresta). Para $\Delta \mathrm{T}$ maior que $8{ }^{\circ} \mathrm{C}$, o ambiente é classificado com ilha de calor forte; para $\Delta \mathrm{T}$ entre $5{ }^{\circ} \mathrm{C}$ e 7 ${ }^{\circ} \mathrm{C}$, ilha de calor moderado; e para $\Delta \mathrm{T}$ menor que $4{ }^{\circ} \mathrm{C}$, ilha de frescor (BARROS; LOMBARDO, 2016). Os dados de $\Delta \mathrm{T}$ anuais foram submetidos à análise de regressão, pelo software Bioestat 5.0, para gerar um modelo matemático que descreva a relação de $\Delta \mathrm{T}$ da ilha de Mosqueiro no decorrer dos anos (AYRES et al., 2007).

\section{Aspecto qualitativo}

Para levantamento de informações sobre o uso da terra in loco, realizou-se primeiro uma visita piloto para conhecer a área e estabelecer um contato inicial com membros da comunidade Castanhal do Mari-Mari. Posteriormente, em uma reunião, foi apresentado o projeto e com a concordância das pessoas em participar do mesmo, o líder da comunidade assinou o Termo de Anuência Prévia (TAP) adaptado de Albuquerque e Hanazaki (2006). Tanto o projeto como o TAP foram apresentados ao Comitê de Ética na Plataforma Brasil.

Com aplicação do método de amostragem nãoprobabilístico, adotando o de bola de neve, foram realizadas observações não participantes e três entrevistas não formais (ALBURQUERQUE et al., 2010) direcionadas para o conhecimento da história de vida de moradores da comunidade Castanhal do Marimari - PA, relacionando suas origens, o uso da terra e a percepção quanto às recentes aberturas de estradas na localidade.

Foram realizadas excursões de campo entre agosto de 2014 e outubro de 2016, período em que a equipe fez registros de diversas práticas agriculturais tradicionais e da construção de uma estrada. Em outubro aplicou-se entrevistas direcionadas pelas seguintes perguntas: Qual atividade você desenvolve? Como você prepara a terra para cultivo? O seu sustento é somente da terra? Qual sua opinião sobre a abertura recente da estrada? O que de bom trouxe a abertura da estrada? $\mathrm{O}$ que de negativo a abertura da estrada trouxe à comunidade? Como era sua vida antes da abertura da estrada?

\section{RESULTADOS E DISCUSSÃO}

\section{Uso e cobertura da ilha de Mosqueiro, Pará}

A ilha de mosqueiro apresentou uma extensão florestal de $178.48 \mathrm{~km}^{2}$ em 2010, compreendendo cerca de $17 \%$ da extensão territorial do município de Belém $\left(1.059,45 \mathrm{~km}^{2}\right)$. Em 2015, a área de floresta da ilha passou a ser de $159.2 \mathrm{~km}^{2}$, constatando-se perda de $10.8 \%\left(19.28 \mathrm{~km}^{2}\right)$ da cobertura vegetal registrada em 2010 (Tabela 1). Em contrapartida, verificou-se expansão da classe de área urbana $\left(5.72 \mathrm{~km}^{2}\right.$, $71.28 \%$ ), concentrada na área noroeste da ilha (Figura 2), bem como a intensificação da supressão florestal o que resultou no aumento de $8.29 \mathrm{~km}^{2}$ (54.5\%) de áreas com solo exposto na ilha de Mosqueiro.

Tabela 1. Extensão territorial das classes de uso e cobertura na ilha de Mosqueiro-PA nos anos de 2010, 2013 e 2015.

\begin{tabular}{lccc}
\hline \multirow{2}{*}{ Classes } & \multicolumn{3}{c}{ Área $\left(\mathrm{km}^{2}\right)$} \\
\cline { 2 - 4 } & 2010 & 2013 & 2015 \\
\hline Água & 5.18 & 5.18 & 5.18 \\
Área não observada & 6.23 & 1.03 & 11.48 \\
Área urbana & 14.20 & 16.73 & 19.92 \\
Solo exposto & 9.91 & 16.74 & 18.20 \\
Floresta & 178.48 & 174.3 & 159.2 \\
\hline
\end{tabular}

Figura 2. Cenários para as classes de uso e cobertura da terra na ilha de Mosqueiro, Pará, correspondendo aos anos de 2010, 2013 e 2015.

2010

\section{Uso e cobertura da terra}

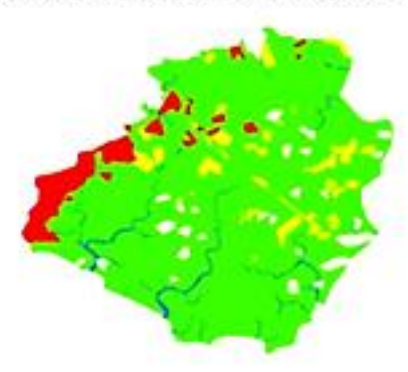

Base de Dados: USGS

Projeçĩo: UTM

Datum: SIRGAS 2000

Março, 2016, Belém - PA
2013

Uso e cobertura da terra
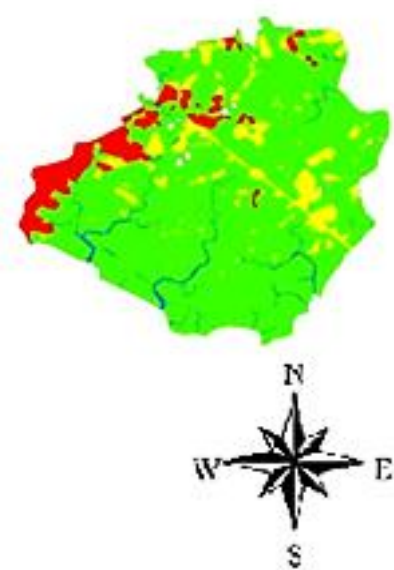

2015
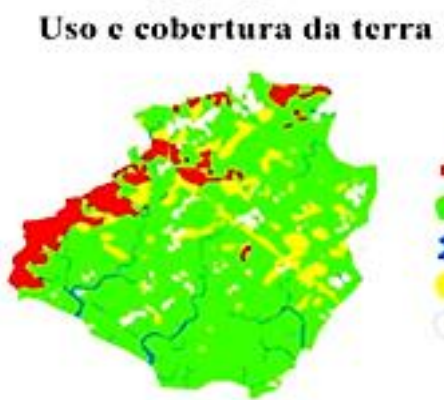

Area Urbana

Floresta

Agua

Solo Exposto

Avea Nao Observada

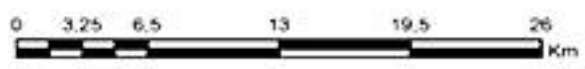


Ao longo dos 5 anos estudados, não foi constatado diferença significativa nas alterações de uso e cobertura da terra $(\mathrm{F}=0.94, \mathrm{p}=0.57)$. No entanto, Corrêa e Silva (2015) verificaram que o avanço das construções urbanas no bairro do Paraíso na ilha de Mosqueiro e a redução de áreas verdes estão inteiramente relacionadas. Esse processo tende a permanecer em ascendência devido principalmente à deficiência no planejamento urbano na ilha, em conjunto com o forte apelo turístico da região pela vasta extensão praiana e o reduzido valor imobiliário das terras, sendo ainda um ponto muito requisitado pela proximidade do centro urbano de Belém-PA (CABRAL et al., 2015).

Outro indicativo de pressão ambiental sobre a ilha se refere ao aumento das áreas de solo exposto no limiar da rodovia Augusto Meira Filho (PA-319), a principal via de acesso à ilha que perpassa pelo centro da ilha até o litoral (Figura 2), tornando-se perceptível o padrão de desmatamento ao longo das estradas durante o período de estudo, principalmente no ano de 2015. Processo semelhante e mais intenso ocorreu com a rodovia Cuiabá-Santarém (BR-163) e Manaus-Porto Velho (BR-319), as quais permitiram acesso às vastas áreas de florestas relativamente intactas, consequentemente, implicam em grandes áreas desmatas no seu entorno (FEARNSIDE, 2006; FEARNSIDE; LAURANCE, 2012).

As populações tradicionais da ilha de Mosqueiro possuem a agricultura como principal fonte de renda e subsistência (GONÇALVES et al., 2016). Essa atividade também é associada ao aumento de áreas com solo exposto pelo emprego da prática convencional de corte e queima da vegetação no preparo do solo (PEDROSO-JUNIOR et al., 2008).

Na perspectiva de moradores da comunidade Castanhal do Marimari, localizada nas proximidades do rio Marimari na ilha de Mosqueiro, as melhorias ao acesso urbano, ou seja, as aberturas de estradas proporcionam benefícios à comunidade, corroborados com a verbalização de uma moradora: "foi muito bom pra gente [...] quando a gente quer trazer as coisas era tudo de barco [...], passava maior trabalho, embarca e desembarca" (Sra. L.). Haja vista que o acesso era unicamente por meio de embarcações através do rio Tamanduaquara (QUARESMA et al., 2008).

No entanto, a abertura da estrada que liga a Rodovia Augusto Meira Filho à sede da comunidade intensificou o desmatamento na ilha, principalmente, no entorno da mesma por atividade de loteamento, de posseiros, de extração madeireira e de agricultores familiares. De acordo com Ferreira et al. (2005), nas proximidades das estradas é comumente encontrada grandes áreas desmatadas, fato também observado na fala do morador da ilha e na Figura 3:

"Depois que abriu a estrada aí foi quem mais veio dos herdeiros. Vieram e foram mexendo e mexendo [...] não moram aqui e uns moram. E a gente para não perder pro que vem de fora, isso aqui é meu também [...]. Não era assim antigamente, ninguém cercava [...]. De primeiro, nós tirava um pouco (madeira) se fosse pra usar pra fazer uma casa, vendi até umas motosserras [...]. Nós mais faz a roça na nossa área [...] nós roça, queima, ajunta, cava e coloca a mandioca [...] a gente tá plantando muito açaí e pupunha" (Sr. A.).

Figura 3. Abertura da estrada de acesso à comunidade Castanhal do Marimari, na ilha de Mosqueiro (0107'54.0"S e $48^{\circ} 22^{\prime \prime 35.3 ” W) ~(A) ~ e ~ r e g i s t r o s ~ s u p r e s s a ̃ o ~ n o ~ l i m i a r ~ d a ~ e s t r a d a ~(B), ~ p a r a ~ o c u p a c ̧ a ̃ o ~ h u m a n a ~(C) ~ e ~ p a r a ~ c e r c a m e n t o ~ d e ~ a ́ r e a ~(D) . ~}$
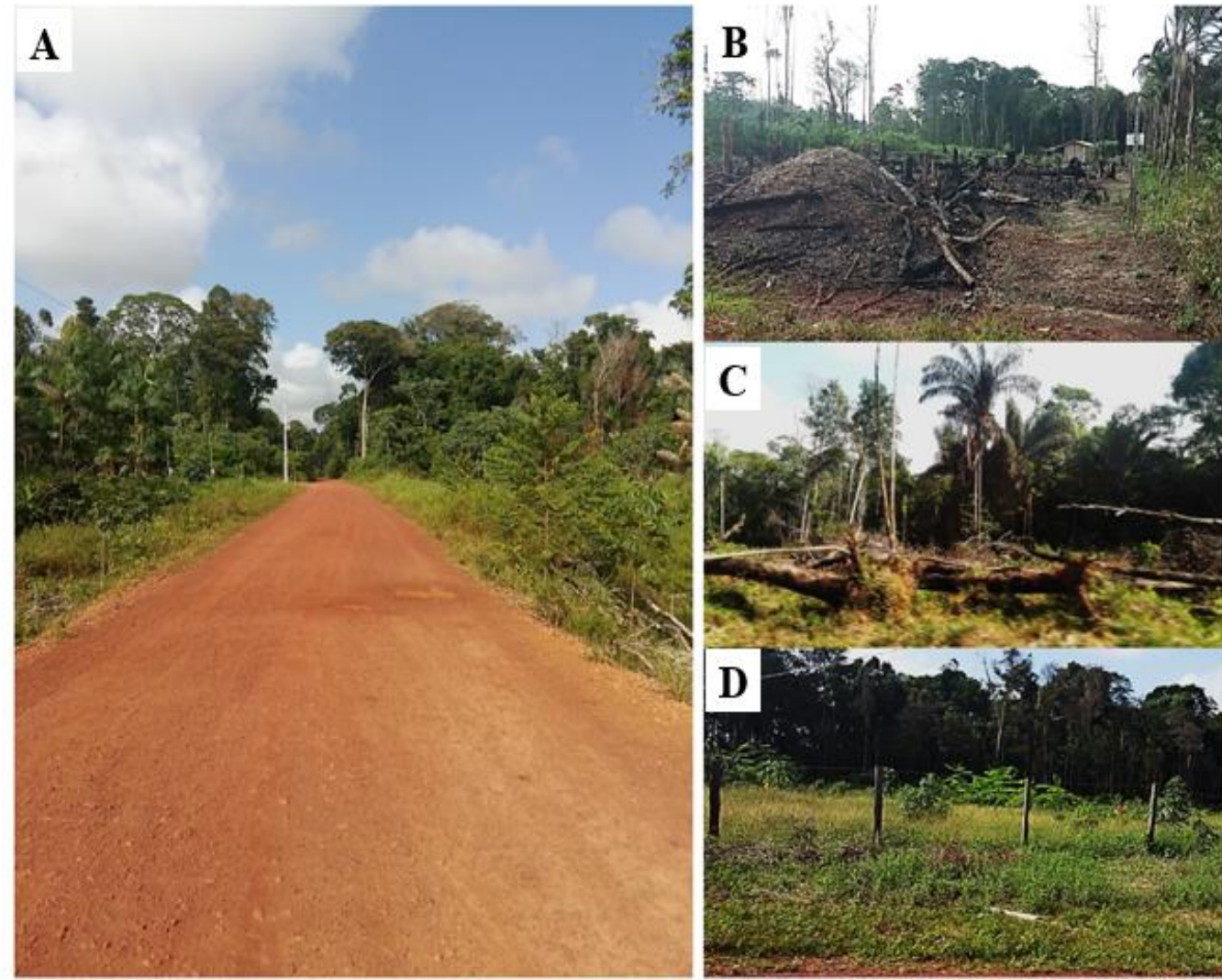

Fonte: Autores (2018) 
Variações térmicas do uso e cobertura da ilha de Mosqueiro, Pará

Entre os anos de 2010, 2013 e 2015, constatou-se diferença significativa na temperatura de superfície (TS) média da ilha de Mosqueiro ( $\mathrm{F}=94,35 ; \mathrm{p}<0,01)$. De acordo com o teste Tukey a diferença encontrada está entre o ano de 2010, considerado o mais ameno com temperatura de $21.2^{\circ} \mathrm{C}$, em relação a $2013\left(24.65{ }^{\circ} \mathrm{C}, \mathrm{Q}=14.25, \mathrm{p}<0.01\right)$ e 2015 $\left(25.84{ }^{\circ} \mathrm{C}, \mathrm{Q}=18.56, \mathrm{p}<0.01\right)$.

Figura 4. Cenários de variações térmicas na ilha de Mosqueiro, Pará, correspondendo aos anos de 2010, 2013 e 2015.
2010

Temperatura de Superficie

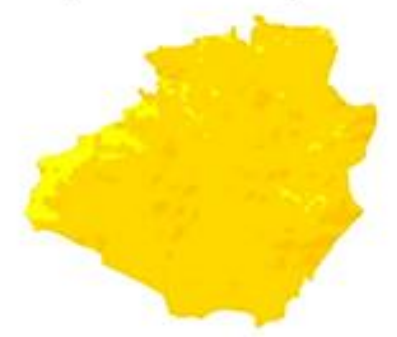

Base de Dados: USGS
Projeção: UTM
Datum: SIRGAS 2000
Março, 2016, Belém - PA
2013

Temperatura de Superficie
Mesmo que 2015 corresponda ao ano de influência do fenômeno de grande escala na região (El Niño), neste período esse evento foi classificado como um dos mais intensos já registrado (PEREIRA et al., 2017), não foi identificado diferença na TS entre o ano de 2013. Embora, a temperatura de todas as classes de uso da terra tenha aumentado em média $1.2{ }^{\circ} \mathrm{C}$ devido o prolongamento da estiagem na região (Figura 4).

\section{5}

\section{Temperatura de Superficie}
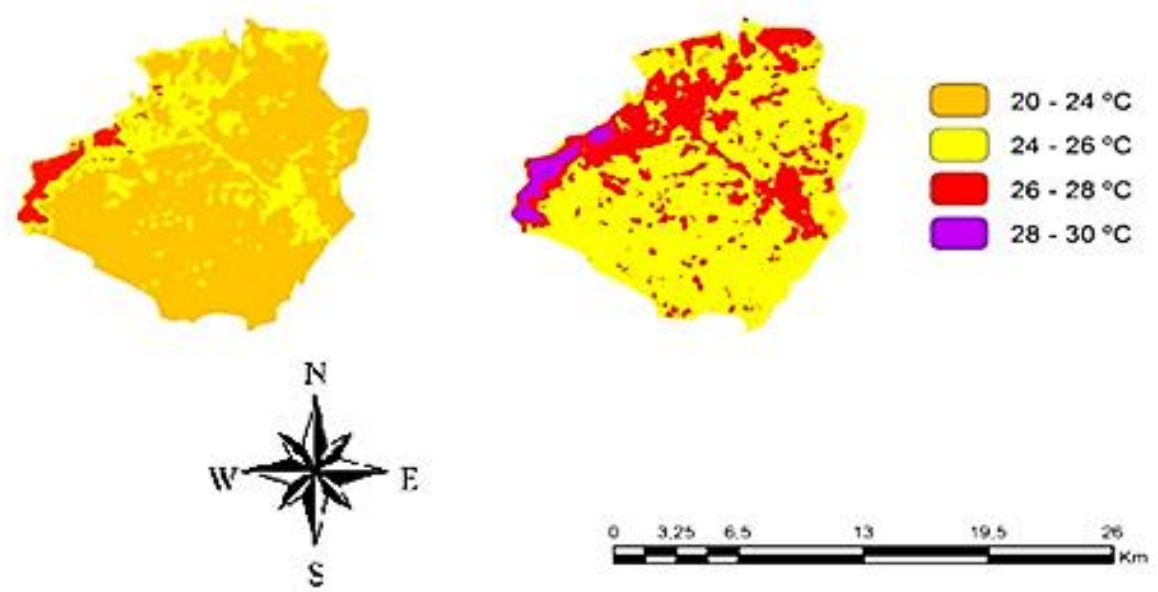

A área mais quente da ilha de mosqueiro se concentrou na região noroeste, com temperaturas entre $24{ }^{\circ} \mathrm{C}$ a $26^{\circ} \mathrm{C}$ em 2010, $26{ }^{\circ} \mathrm{C}$ a $28{ }^{\circ} \mathrm{C}$ em 2013 e $28{ }^{\circ} \mathrm{C}$ a $30{ }^{\circ} \mathrm{C}$ em 2015 (Figura 4). Esses locais coincidem com os maiores valores de temperatura de superfície por se tratar da malha urbana da 5A).

Figura 5. Relação entre a temperatura de superfície e as classes de área urbana (A), solo exposto (B) e área de floresta (C) ao longo dos anos de 2010, 2013 e 2015.

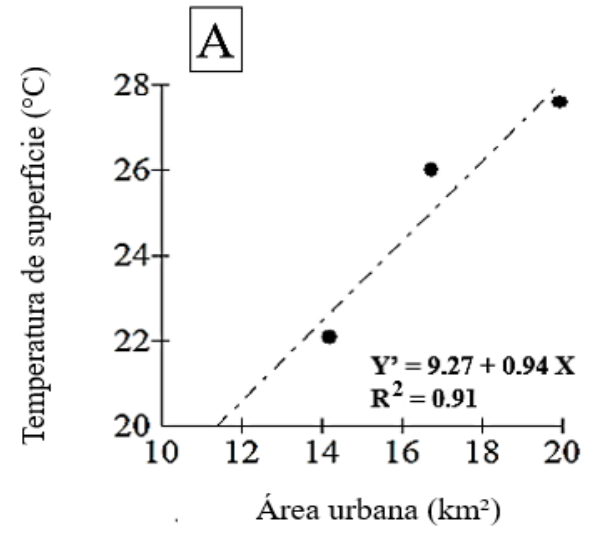

De modo semelhante, a expansão da classe de solo exposto também apresentou forte relação com a elevação da temperatura de superfície $(\mathrm{r}=0.99)$, observado na Figura $5 \mathrm{~B}$. Segundo Mashiki e Campos (2013), essa classe é oriunda de processos relacionados à supressão vegetal, seja para abertura de estradas ou para implantação da agricultura ou para produção de carvão mineral, que pela inexistência de cobertura vegetal a área recebe diretamente a radiação solar, o que ocasiona o rápido aquecimento e aumento da irradiação nessas áreas. ilha com estrutura física dominadas por solo revestido, telhados e mármores (DING; SHI, 2013). Além disso, verificou-se que a expansão da área urbana apresentou forte correlação com o aumento da temperatura $(r=0.95$, Figura

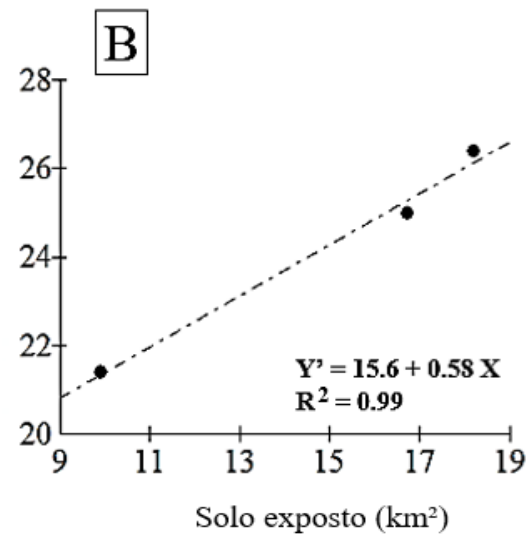

Como a maior parte da ilha de Mosqueiro é coberta por floresta densa houve a predominância de temperatura mais amenas, com gradiente variando entre $20{ }^{\circ} \mathrm{C}$ e $26{ }^{\circ} \mathrm{C}$ nos anos estudados (Figura 4). Em decorrência ao sombreamento e ao processo de termorregulação das árvores, a cobertura florestal é capaz de manter temperaturas mais baixas (ABREU; LABAKI, 2010, MASHIKI; CAMPOS, 2013). Esse fato justifica a relação inversa entre TS e a área de floresta ( $\mathrm{r}=$ 0.87, Figura 5C).

Nas margens da área urbana da ilha que formam fronteira com a floresta (região noroeste - Figura 4), 
observou-se a funcionalidade desta em amenizar o clima urbano ao criar uma zona periférica com temperaturas mais amenas variando entre $20{ }^{\circ} \mathrm{C}$ a $24{ }^{\circ} \mathrm{C}$, no ano de 2010; $24{ }^{\circ} \mathrm{C}$ a $26{ }^{\circ} \mathrm{C}$, no ano de 2013 , e $26{ }^{\circ} \mathrm{C}$ a $28{ }^{\circ} \mathrm{C}$, em 2015 . Tais resultados estão de acordo com Martini et al. (2015), os quais diagnosticaram que as áreas de floresta atuam positivamente ao amenizar o microclima nos arredores imediatos de ambiente urbanizado.

Com relação a diferença de temperatura de superfície entre as áreas urbanas e as áreas de floresta $(\Delta \mathrm{T})$, verificou-se que os valores variaram entre $1.3^{\circ} \mathrm{C}$ e $1.8^{\circ} \mathrm{C}$ entre os anos de 2010 e 2015 (Tabela 2). Embora seja perceptível a elevação térmica no aglomerado urbano da ilha de Mosqueiro (Figura 4), o clima nesse espaço foi classificado como ilha de frescor $\left(\Delta \mathrm{T}<4^{\circ} \mathrm{C}\right)$ em resposta da grande concentração de floresta na ilha, a qual é responsável por amenizar o clima local (BARROS; LOMBARDO, 2016).

Tabela 2. Média por classe de uso e cobertura da temperatura de superfície (TS) na ilha de Mosqueiro-PA nos anos de 2010,2013 e 2015.

\begin{tabular}{lccc}
\hline \multirow{2}{*}{ Classes } & \multicolumn{3}{c}{ Média da TS $\left({ }^{\circ} \mathrm{C}\right)$} \\
\cline { 2 - 4 } & 2010 & 2013 & 2015 \\
\hline Água & 20.5 & 23.5 & 23.5 \\
Área não observada & - & - & - \\
Área urbana & 22.1 & 26.0 & 27.6 \\
Solo exposto & 21.4 & 25.0 & 26.4 \\
Floresta & 20.8 & 24.1 & 25.8 \\
\hline \multirow{2}{*}{$\Delta \mathrm{T}$} & 1.3 & 1.9 & 1.8 \\
$\left(\mathrm{TS}_{\text {área urbana }}-\mathrm{TS}_{\text {Floresta }}\right)$ & Ilha de & Ilha de & Ilha de \\
& frescor & frescor & frescor \\
\hline
\end{tabular}

Com a deficiência no planejamento urbano que a ilha de Mosqueiro vivencia (CABRAL et al., 2015) e com a crescente elevação da diferença de temperatura do centro urbano e seu entorno, em 50 anos o espaço urbano da ilha de Mosqueiro constituirá em uma ilha de calor moderada se esse cenário persistir (Figura 6). E, em 73 anos será considerada como ilha de calor forte. Salienta-se que as estimativas feitas com base na regressão linear e que respondem a $85 \%$ de confiança $(\mathrm{R} 2=0.85)$.

Figura 6. Relação entre a diferença da temperatura de superfície (TS) das classes de área urbana e de floresta $(\Delta T)$ longo dos anos de 2010, 2013 e 2015.

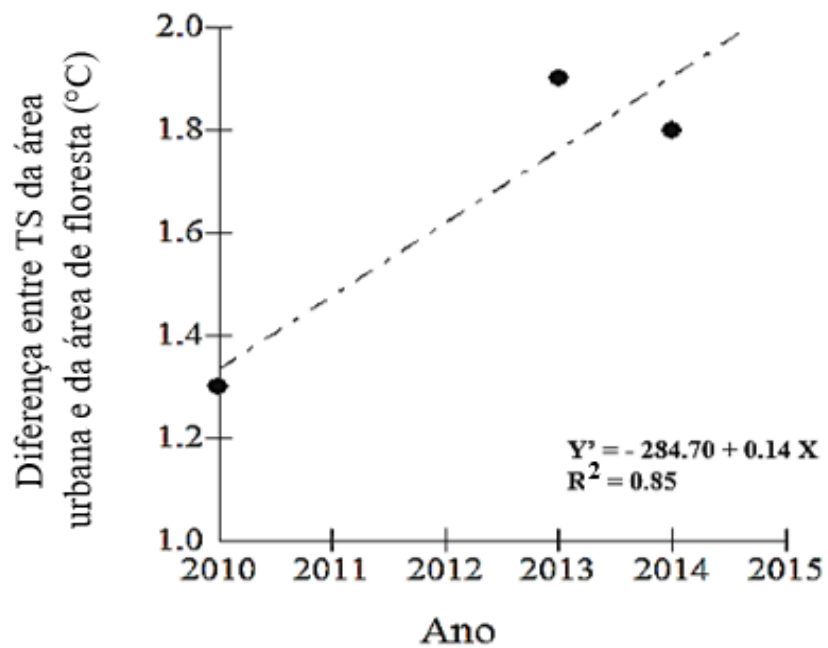

\section{CONCLUSÕES}

As modificações na paisagem da ilha de Mosqueiro, Pará, estão relacionadas com o aumento na temperatura de superfície, mesmo que o espaço urbano ainda se constitua como um ambiente de ilha de frescor.

Com o crescimento desordenado da área urbana e das áreas com solo exposto, classes que estão diretamente relacionadas com o aumento da temperatura de superfície, bem como a redução das áreas de floresta que apresentaram a funcionalidade de amenizar o clima urbano, o cenário climático local seguirá para o lado pessimista com aumento contínuo da temperatura. Fato que evidencia a necessidade de melhoria nas estratégias de planejamento urbano da ilha para evitar a concretização desse cenário.

\section{REFERÊNCIAS}

ABREU, L. V.; LABAKI, L. C. Conforto térmico propiciado por algumas espécies arbóreas: avaliação do raio de influência através de diferentes índices de conforto. Ambiente Construído, v. 10, n. 4, p. 103-117, 2010.

ALBUQUERQUE, U. P.; HANAZAKI, N. As pesquisas etnodirigidas na descoberta de novos fármacos de interesse médico e farmacêutico: perspectivas e fragilidades. Revista Brasileira Farmacognosia, v. 16, p. 678 - 689, 2006.

ALBURQUERQUE, U. P. de; LUCENA, R. F. de P.; ALENCAR, N. L. Métodos e técnicas para coleta de dados etnobiológicos. In: ALBURQUERQUE, U. P. de; LUCENA, R. F. de P.; CUNHA, L. V. F. C. da (Eds.). Métodos e Técnicas na Pesquisa Etnobiológica e Etnoecológica. Recife, PE: NUPPEA, 2010. p. 39-64.

AMORIM, M. C. C. T.; DUBREUIL, V.; QUENOL, H.; SANT'ANA NETO, J. L. Características das ilhas de calor em cidades de porte médio: exemplos de Presidente Prudente (Brasil) e Rennes (França). Confins, n. 7, p. 1-16, 2009.

AYRES, M.; AYRES JÚNIOR, M.; AYRES, D. L.; SANTOS, A. S. dos. BioEstat: aplicações estatísticas nas áreas das ciências biológicas e médicas. Belém: Sociedade Civil Mamirauá, 2007.

BARBOSA, R. V. R.; VECCHIA, F. A. S. Estudos de ilha de calor urbana por meio de imagens do Landsat 7 ETM +: estudo de caso em São Carlos (SP). Minerva, v. 6, n. 3, p. 273-278, 2009.

BARROS, H. R.; LOMBARDO, M. A. A ilha de calor urbana e o uso e cobertura do solo em São Paulo-SP. Geousp Espaço e Tempo (online), v. 20, n. 1, p. 160-177, 2016.

CABRAL, E. R.; DIAS, J. S.; GOMES, S. C. Gestão ambiental em espaços de lazer e turismo: As praias urbanas da Amazônia brasileira. Rosa dos Ventos, v. 7, n. 2, p. 269287, 2015.

COELHO, A. L. N.; CORREA, W. S. C. Temperatura de superfície celsius do sensor Tirs/Landsat-8: metodologia e aplicações. Revista Geográfica Acadêmica, v. 7, n. 1, p. 3145, 2013.

CORRÊA, R. S.; SILVA, R. V. B. Ocupação urbana e degradação ambiental: ocupação, simbolismo e cidadania 
ambiental no bairro do Paraíso, Mosqueiro - PA. Revista Perspectivas do Desenvolvimento: um enfoque multidimensional, v. 3, n. 4, p. 1-25, 2015.

CORREA, W. S. C.; COELHO, A. L. N.; VAlE, C. C. V. Influência de distintos sistemas atmosféricos na temperatura de superfície do município de Vitória (ES). Caminhos de Geografia, v. 16, n. 53, p. 37-54, 2015.

COSTA, J. M.; PIETROBOM, M. R. Pteridófitas (Lycophyta e Monilophyta) da Ilha de Mosqueiro, município de Belém, estado do Pará, Brasil. Boletim do Museu Paraense Emílio Goeldi Ciências Naturais, v. 2, n. 3, p. 45-56, 2007.

DING, H.; SHI, W. Land-use/land-cover change and its influence on surface temperature: a case study in Beijing city. International Journal of Remote Sensing, v. 34, n. 15, p. 5503-5517, 2013.

FEARNSIDE, P. M. Desmatamento na Amazônia: dinâmica, impactos e controle. Acta Amazônica, v. 36, n. 3, p. 395-400, 2006.

FEARNSIDE, P. M.; LAURANCE, W. F. Infraestrutura na Amazônia: as lições dos planos plurianuais. Caderno CRH, v. 25, n. 64, p. 87-98, 2012.

FERREIRA, L. V.; VENTICINQUE, E.; ALMEIDA, S. O desmatamento na Amazônia e a importância das áreas protegidas. Estudos avançados, v. 19, n. 53, p. 157-166, 2005.

FERREIRA, S. B. A expansão dos assentamentos residenciais na ilha de Mosqueiro: uma particularidade de dispersão urbana no espaço metropolitano de Belém (PA). Belém: UFPA, 2012. 139p.

GONÇALVES, A. C. O.; CORNETTA, A.; ALVES, F.; BARBOSA, L. J. Belém e Abaetetuba. In: ALVES, F. (Ed.). A função socioambiental do patrimônio da união na Amazônia. Brasília: Ipea, 2016. p. 359.

IBGE. INSTITUTO BRASILEIRO DE GEOGRAFIA E ESTATÍSTICA. Catálogo. 2018. Disponível em: < https://biblioteca.ibge.gov.br/index.php/biblioteca-

catalogo?view $=$ detalhes $\& i d=42472>$. Acesso em: 18 out 2018.

MARTINI, A.; BIONDI, D.; VIEZZER, J.; SILVA, D. A. O efeito microclimático do fragmento florestal existente no Parque Municipal do Barigui na cidade Curitiba-PR. Ciência e Natura, v. 37, p. 125-131, 2015.

MASHIKI, M. Y.; CAMPOS, S. Influência do uso e ocupação do solo na temperatura aparente da superfície no município de Botucatu/SP. Revista Energia na Agricultura, v. 28, n. 3, p. 143-149, 2013.

MESSIAS, C. G. Análise comparativa entre o mapeamento de uso do solo e cobertura vegetal utilizando imagens de média e alta resolução espacial. Revista Geonorte, v. 2, n. 4, p. 12301243, 2012.

NASCIMENTO, D. T. F.; OLIVEIRA, I. J. de. Análise da evolução do fenômeno de ilhas de calor no município de
Goiânia/GO (1986-2010). Boletim Goiano de Geografia, v. 31, n. 2, p. 113-127, 2011.

OLIVEIRA, N. L.; MARCUZZO, F. F. N.; BARROS, R. G. Influência do El Niño e La Niña no número de dias de precipitação pluviométrica no Estado do Mato Grosso. Ciência e Natura, v. 1982, n. 4, p. 284-297, 2015.

PEDROSO-JUNIOR, N. N.; ADAMS, C.; MURRIETA, R. S. S. A agricultura de corte e queima: um sistema em transformação. Boletim do Museu Paraense Emílio Goeldi, v. 3, n. 2, p. 153-174, 2008.

PEREIRA, H. R.; REBOITA, M. S.; AMBRIZZI, T. Características da Atmosfera na Primavera Austral Durante o El Niño de 2015/2016. Revista Brasileira de Meteorologia, v. 32, n. 2, p. 293-310, 2017.

PRATES, R. C.; BACHA, C. J. C. Os processos de desenvolvimento e desmatamento da Amazônia. Economia e Sociedade, v. 20, n. 3, p. 601-636, 2011.

QUARESMA, H. D. A. B.; SILVA, J. B.; PINTO, M. J.; CAMPOS, R. I. R. Políticas públicas e gestão de recursos florestais: o caso do parque ambiental da ilha do Mosqueiro, Belém/PA. In: Seminário Internacional - Amazônia e Fronteiras do Conhecimento, 1. Anais...Belém: NAEA, 2008. p.16.

RIBEIRO, W. de O.; AUGUSTA, M. F. C.; TAVARES, M. G. da C. As práticas turísticas na orla oeste da Ilha de Mosqueiro, Região Metropolitana de Belém, PA. Rosa dos Ventos, v. 5, n. 3, p. 528-544, 2013.

SANTOS, J. S.; MOTA, M. A. S.; ROCHA, E. J. P. Classificação climatológica da energia potencial disponível para a convecção na cidade de Belém-PA. Revista Brasileira de Meteorologia, v. 29, n. esp., p. 60-72, 2014.

SOUZA, D. O. Influência da ilha de calor urbana nas cidades de Manaus e Belém sobre o microclima local. São José dos Campos: INPE, 2012. 187p.

SOUZA, D. O. de; ALVALÁ, R. C. dos S. Observational evidence of the urban heat island of Manaus City, Brazil. Royal Meteorological Society (online), v. 21, n. 2, p. 186193, 2012.

TAVARES, M. G. da C. GOMES, K. dos S.; COSTA, M. A. F. da; RIBEIRO, W. de O. Turismo e desenvolvimento local em uma ilha fluvial na Região Metropolitana de Belém: o caso da ilha de Mosqueiro na Amazônia brasileira. Revista Universitária de Geografía, v. 16, n. 1, p. 125-145, 2007.

VIEIRA, I. C. G.; SILVA, J. M. C. da; TOLEDO, P. M. Estratégias para evitar a perda de biodiversidade na Amazônia. Estudos Avançados, v. 19, n. 54, p. 153-164, 2005.

XIAO, H.; WENG, Q. The impact of land use and land cover changes on land surface temperature in a karst area of China. Journal of Environmental Management, v. 85, n. 1, p. 245257, 2007. 